\title{
In Vitro Antimicrobial Activity Study of Some New Arginine-based Biodegradable Poly (Ester Urethane)s and Poly (Ester Urea)s
}

\author{
Darejan Kharadze ${ }^{1 *}$, Tamar Memanishvili ${ }^{2}$, Ketevan Mamulashvili ${ }^{3}$, Tina Omiadze ${ }^{1}$, Larisa Kirmelashvili ${ }^{1}$, Zaur \\ Lomtatidze $^{3}$ and Ramaz Katsarava ${ }^{2}$ \\ 1. Department of Bioinformatic, the I. Beritashvili Center of Experimental Biomedicine, Tbilisi 0160, Georgia \\ 2. Institute of Chemistry and Molecular Engineering, the Agricultural University of Georgia, Tbilisi 0159, Georgia \\ 3. Department of Microbiology of Institute of Botany, the Ilia State University, Tbilisi 0162, Georgia
}

\begin{abstract}
Bactericidal activity of some arginine based biodegradable polymers-PEURs (poly (ester urethane)s) and PEUs (poly (ester urea)s) with low cytotoxicity was studied in in vitro experiments. Various bacterial strains both Gram-positive and Gram-negative were used to explore the bactericidal activity of the cationic polymers. As the test objects, the following microorganisms were used: Bacillus subtilis, Staphylococcus aureus, Mycobacterium album, Pseudomonas fluorescens, Escherichia coli, Actinomyces griseus and Aspergillus niger. The obtained results showed that the new cationic polymers suppressed the growth of the studied microorganisms and the bactericidal activity of the tested cationic polymers strongly depending on their chemical structure.
\end{abstract}

Key words: Arginine, cationic polymer, poly (ester urethane), poly (ester urea), bactericidal activity.

\section{Introduction}

The development of synthetic antimicrobial agents is an emerging need due to antibiotic resistance of bacteria causing fatal infectious diseases, which significantly threaten public health in global regions. According to statistics, the number of resistant microbial strains as well as that of antibiotic-immune patients grows a lot faster than the number of useable antibiotics [1-4] that make microbial infections the number one killer in the world. The resistance of bacteria was found initially in hospitals, however, the drug-resistant strains rapidly spread to other public places and communities across countries, and infectious diseases are becoming increasingly less treatable with conventional antibiotics. Hence, new antimicrobial agents are urgently needed, which

\footnotetext{
*Corresponding author: Darejan Kharadze, doctor, research fields: synthesis and investigation of bioanalogous polymers based on natural amino acids.
}

requires new design concepts and approaches to combat drug resistant bacteria.

Considering the wide use of agents as drugs and in consumer products, it would be ideal to create antimicrobials that can meet the following criteria: selective toxicity to bacteria vs. human cells and low susceptibility to the development of resistance in bacteria.

One of the most promising tools in a battle against bacteria is OC (organic cations). Starting from the 1980s three classes of OC have become the most important as bactericidal agents:

- naturally occurring peptides and their analogs;

- low-molecular-weight non-peptide organic molecule;

- bactericidal polymers.

AMPs (Antimicrobial peptides), found in all classes of living organisms, represent a large and unique group of molecules with a broad spectrum of antimicrobial, antifungal, and antiviral activity and are an important part of the innate immune system [5]. 
AMPs normally composed of 12-50 amino acids, are enriched by cationic $\alpha$-amino acids such as arginine (containing guanidine group), lysine or histidine. In spite of many hopes an idea of commercialization of bactericidal peptides turned out less promising due to a high price and instability against enzymes. More promising from commercial point of view look cheaper and stable synthetic analogs [6]. Many representatives of the second class of organic bactericides also contain guanidine group. Among these compounds one of the most known and widely used is chlorohexidine (as bis-gluconate salt) [7]. Following to the successful applications of chlorohexidine a family of substituted guanidines with a wide range of properties was obtained and studied during the last two decades [8,9]. Nevertheless, it should be noted here that low-molecular-weight antimicrobials have one common limitation which consists in short-term antimicrobial ability.

In contrast to low-molecular-weight analogs bactericidal polymers are characterized by prolonged action, as well as higher antimicrobial ability due to a high local concentration of the active groups. The highly charged cationic molecule was shown to permeates the outer membrane and partly depolarizes the inner one. Moreover, it has been demonstrated that cationic molecule is distributed widely in the bacterial cell at lethal concentrations, and could bind to DNA. It was confirmed that the multimodal action of the cationic molecule resulted in it being less likely to lead to resistance development as compared to single-target antibiotics [10]. Presumably, this type of bactericidal mechanism is valid for other organic molecules, especially for highly charged cationic polymers. Similar to the above low-molecular-weight bactericides, PBs (polymeric bactericides) containing guanidine group are one of the most promising for therapeutic applications. The first polymer that became a commercial disinfectant was poly (hexamethylene biguanidinium hydrochloride) [11]. Various guanidine/biguanidine-group containing PBs such as the corresponding polyacrylates and polymethacrylates were reported as well [12].

It is worthy note here that guanidine-group containing antimicrobials were found to be significantly less toxic compared to the ammonium functionality, especially quaternary ammonium functionality (that exists e.g. in poly (ethylene imine) and its derivatives) that was ascribed to a high delocalization of positive charge in guanidine compared to the ammonium functionality [13]. It is also important to have biodegradable PBs that will be cleared from or assimilated by the body after their function is fulfilled. Hence, synthetic polymers composed of amino acid arginine, which contains guanidine group as a lateral substituent and represents a normal metabolic component of vital activity, are of special interest as bactericides. A high water-solubility of PBs is also very important for their practical applications.

Very recently the authors have reported on the synthesis of a family of arginine-based cationic ester-ether polymers [14] which meet all these requirements. The backbones of these polymers contain ester bonds that provide biodegradability and ether bonds that impart a poly (ethylene glycol)-like structure and, accordingly, better water solubility. The polymers of various classes-PEAs (poly (ester amide)s), PEEAs (poly (ester ether amide)s), PEURs (poly (ester urethane)s), PEEURs (poly (ester ether urethane)s), PEUs (poly (ester urea)s), and PEEUs (poly (ester ether urea)s) were obtained by solution active polycondensation of tetra- $p$-toluenesulfonic acid salts of bis-(L-arginine)-alkylene diesters with activated diesters of various classes. The structures of the new cationic polymers are depicted in Fig. 1.

The new cationic polymers showed good solubility in wáter and biodegradability along with excellent cell compatibility. The present paper deals with bactericidal activity study of the some selected samples of the new arginine-based cationic polymers [14]. 


\section{Materials and Methods}

The seven arginine-based polymers selected for studying bactericidal activity spanned several classes and were: 1-Arg-2 and 1-Arg-3 (PEUs), EG-Arg-3 (PEUR), EG E $_{2}$ Arg-2, EG EG $_{2}$ Arg-3， EG EG $_{2}$ Arg-EG 2 , $\mathrm{EG}_{2}-\mathrm{Arg}-\mathrm{EG}_{4}$ (PEEURs). The polymers were synthesized and characterized as the authors reported previously [14].

Both Gram-positive and Gram-negative microorganisms were used in the present study: Bacillus subtilis, Staphylococcus aureus, Mycobacterium album (Gram-positive), Escherichia coli, Pseudomonas fluorescens (Gram-negative), as well as Aspergillus niger and Actinomyces griseus.

The nutrient medium was prepared depending on the nature of test-microorganisms and method used. For<smiles>CC(C)(C)CC(=O)NC(CCNC(N)=NCO)C(=O)OOOC(=O)C(CCCNC(N)=NC(=O)O)NC(=O)C(C)(C)C</smiles>

bacteria Bacillus subtilis, Staphylococcus aureus, Mycobacterium album, Pseudomonas fluorescens, Escherichia coli the authors used the medium containing agar - Mycobacterium yeast extract medium (nutrient agar), also liquid medium (nutrient broth) from Sigma-Aldrich Chemie GmbH. For fungi Aspergillus niger the medium was prepared according to In Guide for investigations in microbiology and virology [15], Agarinized nutrient medium (solid): one liter of sterilized wort was added to $18 \mathrm{~g}$ of agar and heated until complete dissolution of agar. The obtained medium was poured into sterilized test tubes or Petri dishes and sterilized at $110{ }^{\circ} \mathrm{C}$ for $10 \mathrm{~min}$. For Actinomyces griseus the medium was prepared according to Krasilnikov's synthetic agarinized medium $\mathrm{CP}-1[16]: \mathrm{KNO}_{3}-1 \mathrm{~g}, \mathrm{~K}_{2} \mathrm{HPO}_{4}-0.5 \mathrm{~g}$,

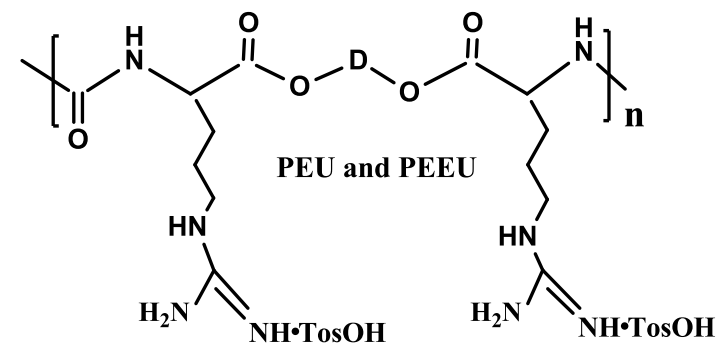

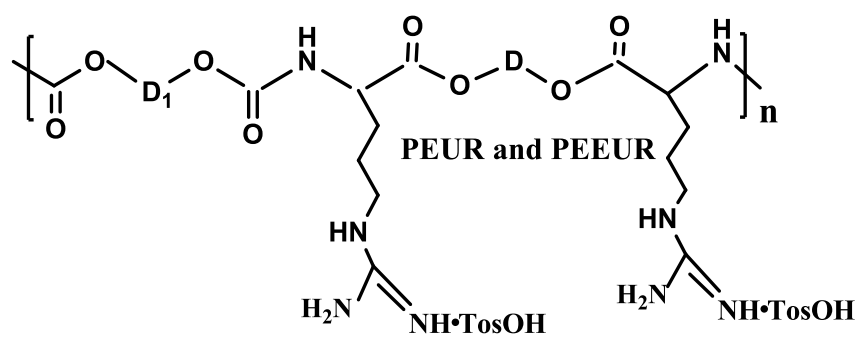

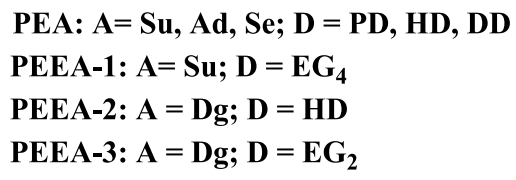

PEUR: $\mathrm{D}_{1}=\mathrm{ED}, \mathrm{PD} ; \mathrm{D}=\mathrm{PD}$

PEEUR-1: $D_{1}=P D ; D=E_{4}$

PEEUR-2: $D_{1}=E_{2} ; \mathrm{D}=\mathrm{ED}, \mathrm{PD}, \mathrm{HD}$

PEEUR-3: $D_{1}=E_{2}, E_{4} ; D=E_{2}, E_{3}, E_{4}$

PEU: D = ED, PD

PEEU: $D=\mathrm{EG}_{\mathbf{2}}, \mathrm{EG}_{\mathbf{4}}$

Fig. 1 The structures of the Arg-based polymers: PEA and PEEA, PEUR and PEEUR, PEU and PEEU. ED, PD, HD, DD, $\mathbf{E G}_{2}, \mathbf{E G}_{3}$, and $\mathbf{E G}_{\mathbf{4}}$ mean the residues (skeletons) of corresponding diols: 1, 2-ethanediol, 1, 3-propanediol, 1, 6-hexanediol, 1, 12-dodecanediol, and di-, tri- and tetra-ethylene glycols. Su, Ad, Se and Dg mean the residues (skeletons) of corresponding diacids: succinic, adipic, sebacic and diglycolic acids. 
$\mathrm{MgSO}_{4}-0.5 \mathrm{~g}, \mathrm{FeSO}_{4}$-traces, $\mathrm{CaCO}_{3}-1 \mathrm{~g}$, starch-20 g, agar-20 g, water-1 L. Sterilization under atmospheric conditions at $120^{\circ} \mathrm{C}$ for $30 \mathrm{~min}$.

Activity of Arg-based polymers against different strains of bacterial species the authors performed using standard protocols of DDM (Disc Diffusion Method) [17] and serial dilution method [18, 19]. These methods were applied to establish the MIC (minimum inhibitory concentration) of the substance-the quantitative index of the microbiological activity of the AMP (antimicrobial preparation).

The standard biomass of the test-microorganisms, equivalent to $0.5 \mathrm{McF}$ arland and diluted 100 times with MPB (meat-peptone broth), was used for inoculation. The presumable amount of microorganisms there might be $10^{6}$ colony-forming units $(\mathrm{CFU} / \mathrm{mL})$.

The experimental solution of the AMP was prepared from the stock-solution, using the MPB. The ultimate concentration of the stock-solution and permissible concentration of the minimal inhibiting dose for the tested strains should be taken into account. The incubation time: $24 \mathrm{~h}$ for bacteria, and 7 days for fungi and actinomycete.

The essence of the disc-diffused method used for the determination of sensitivity of the AMP is as follows: the suspension of the test-microorganisms (the standard biomass of the test-microorganisms, equivalent to $0.5 \mathrm{McFarland)}$ is spread on the Petri dishes and sterilized standard discs (diameter $10 \mathrm{~mm}$, Sigma-Aldrich Chemie $\mathrm{GmbH}$ ), containing the particular concentration of the AMP $(0.001 \mathrm{mg} / \mathrm{mL}$, $0.01 \mathrm{mg} / \mathrm{mL}, 0.1 \mathrm{mg} / \mathrm{mL}$ etc.), are placed on it. The distance between discs-15-20 mm. The AMP which diffused through the agar inhibited the microorganisms growth and zones of inhibition, surrounding the discs, were formed; the zones of inhibition were measured after $24 \mathrm{~h}$ of inoculation. Three runs for each concentration of the AMP were done, mean values were calculated and used for characterizing the diameter of the inhibition zone.
To assess the influence of the AMP at different stages of development of the test-microorganisms, their growth in a liquid medium was studied. The quantity of biomass formed was assessed by OD (optical density) at $\lambda=500 \mathrm{~nm}$ using Photoelectrocolorimeter (PhEC-2-UkhL-4.2. Ru).

According to the obtained data (the zone of inhibition of AMP and MIC) the authors differentiated the polymers as having low, medium and high activity. The microorganisms were divided into sensitive, moderately resistant and resistant forms. For corresponding the obtained data with NOCLS (National Committee for Clinical Laboratory Standards) [20-22] and to merge these three categories the so called bordering concentrations were used.

\section{Results and Discussions}

The authors have studied biocidal activity of two PEUs 1-Arg-2 and 1-Arg-3, one poly (ester urethane) EG-Arg-3 and four PEEURs EG E $_{2}$ Arg-2, EG 2 -Arg-3, $\mathrm{EG}_{2}-\mathrm{Arg}-\mathrm{EG}_{2}$ and $\mathrm{EG}_{2}-\mathrm{Arg}-\mathrm{EG}_{4}$ at concentrations $10^{-1}$ $\mathrm{mg} / \mathrm{mL}, \quad 10^{-2} \mathrm{mg} / \mathrm{mL}$ and $10^{-3} \mathrm{mg} / \mathrm{mL}$. Seven test-microorganisms were used in this biocidal activity study.

The obtained results are listed in Table 1 .

The PEUs 1-Arg-2 and 1-Arg-3 suppressed the growth of Aspergillus niger, Pseudomonas fluorescens and Staphilococcus aureus (Table 1. \# 5-7). With other microorganisms within the concentrations studied $\left(10^{-1}-10^{-3} \mathrm{mg} / \mathrm{mL}\right)$ these polymers showed no activity.

The poly (ester urethane) EG-Arg-3 and PEEURs $E_{2}-A r g-2$ and $E_{2}-A r g-E_{2}$ were active with only one microorganism-Actinomyces griseus: the first one at a concentrations $10^{-1} \mathrm{mg} / \mathrm{mL}$, the second one at $10^{-1}$ $\mathrm{mg} / \mathrm{mL}$ and $10^{-2} \mathrm{mg} / \mathrm{mL}$, and the third one at all the three concentrations $-10^{-1} \mathrm{mg} / \mathrm{mL}, 10^{-2} \mathrm{mg} / \mathrm{mL}$ and $10^{-3}$ $\mathrm{mg} / \mathrm{mL}$. The PEEURs $\mathrm{EG}_{2}-\mathrm{Arg}-3$ and $\mathrm{EG}_{2}-\mathrm{Arg}-\mathrm{EG}_{4}$ showed wider spectrum of activity-they supressed the growth of the four microorganisms-Bacillus subtilis, Mycobacterium album, E. coli and Aspergillus niger, mostly at higher concentration $\left(10^{-1} \mathrm{mg} / \mathrm{mL}\right)$, at 
Table 1 Biocidal effect of the obtained cationic polymers on the test-microorganisms.

\begin{tabular}{|c|c|c|c|c|c|c|c|c|c|c|c|c|c|c|c|c|c|c|c|c|c|c|}
\hline \multirow{5}{*}{ \# } & \multirow{5}{*}{$\begin{array}{l}\text { Test- } \\
\text { microorganisms }\end{array}$} & \multicolumn{21}{|c|}{ Cationic polymer } \\
\hline & & \multicolumn{4}{|c|}{$1-\operatorname{Arg}-2$} & \multicolumn{2}{|c|}{$1-\operatorname{Arg}-3$} & \multicolumn{3}{|c|}{ EG-Arg-3 } & \multicolumn{3}{|c|}{$\mathrm{EG}_{2}-\mathrm{Arg}-2$} & \multicolumn{3}{|c|}{$\mathrm{EG}_{2}-\mathrm{Arg}-3$} & \multicolumn{3}{|c|}{$\mathrm{EG}_{2}-\mathrm{Arg}-\mathrm{EG}_{2}$} & \multicolumn{3}{|c|}{$\mathrm{EG}_{2}-\mathrm{Arg}-\mathrm{EG}_{4}$} \\
\hline & & \multicolumn{21}{|c|}{ Concentration of cationic polymer, $\mathrm{mg} / \mathrm{mL}$} \\
\hline & & $10^{-1}$ & $10^{-2}$ & $10^{-3}$ & $10^{-1}$ & $10^{-2}$ & $10^{-3}$ & $10^{-1}$ & $10^{-2}$ & $10^{-3}$ & $10^{-1}$ & $10^{-2}$ & $10^{-3}$ & $10^{-1}$ & $10^{-2}$ & $10^{-3}$ & $10^{-1}$ & $10^{-2}$ & $10^{-3}$ & $10^{-1}$ & $10^{-2}$ & $10^{-3}$ \\
\hline & & \multicolumn{21}{|c|}{ Zone of suppression of the test-microorganisms (mm) } \\
\hline 1 & Bacillus subtilis & 0.0 & 0.0 & 0.0 & 0.0 & 0.0 & 0.0 & 0.0 & 0.0 & 0.0 & 0.0 & 0.0 & 0.0 & 3.0 & 0.0 & 0.0 & 0.0 & 0.0 & 0.0 & 6.5 & 0.0 & 0.0 \\
\hline 2 & Mycobacterium album & 0.0 & 0.0 & 0.0 & 0.0 & 0.0 & 0.0 & 0.0 & 0.0 & 0.0 & 0.0 & 0.0 & 0.0 & 2.0 & 0.0 & 0.0 & 0.0 & 0.0 & 0.0 & 4.0 & 0.0 & 0.0 \\
\hline 3 & Escherichia coli & 0.0 & 0.0 & 0.0 & 0.0 & 0.0 & 0.0 & 0.0 & 0.0 & 0.0 & 0.0 & 0.0 & 0.0 & 2.0 & 0.0 & 0.0 & 0.0 & 0.0 & 0.0 & 4.0 & 0.0 & 0.0 \\
\hline 4 & Actinomyces griseus & 0.0 & 0.0 & 0.0 & 0.0 & 0.0 & 0.0 & 3.5 & 0.0 & 0.0 & 7.0 & 7.0 & 0.0 & 0.0 & 0.0 & 0.0 & 5.0 & 3.0 & 3.0 & 0.0 & 0.0 & 0.0 \\
\hline 5 & Aspergillus niger & 1.0 & 0.5 & 0.5 & 1.0 & 0.5 & 0.5 & 0.0 & 0.0 & 0.0 & 0.0 & 0.0 & 0.0 & 1.5 & 1.0 & 1.0 & 0.0 & 0.0 & 0.0 & 2.0 & 1.0 & 1.0 \\
\hline 6 & Pseudomonas fluorescens & 3.0 & 2.0 & 1.0 & 2.0 & 1.0 & 1.0 & 0.0 & 0.0 & 0.0 & 0.0 & 0.0 & 0.0 & 0.0 & 0.0 & 0.0 & 0.0 & 0.0 & 0.0 & 0.0 & 0.0 & 0.0 \\
\hline 7 & Staphilococcus aureus & 1.0 & 0.5 & 0.5 & 1.5 & 1.0 & 1.0 & 0.0 & 0.0 & 0.0 & 0.0 & 0.0 & 0.0 & 0.0 & 0.0 & 0.0 & 0.0 & 0.0 & 0.0 & 0.0 & 0.0 & 0.0 \\
\hline
\end{tabular}


the latter polymer showed $c a$. twice higher activity. Thus, the obtained results showed that all the tested polymers revealed a selective bactericidal activity.

To determine at which stage of the microorganisms' development the tested polymer exposed biocidal activity, bacteria growth was studied in liquid medium (nutrient broth). The poly (ether ester urethane) $\mathrm{EG}_{2}$-Arg-EG $\mathrm{EG}_{4}$ was selected to study the influence on growth of the following microorganisms: Escherichia coli, Bacillus subtilis, Mycobacterium album. The biomass of the microorganisms was determined (by OD at $\lambda=500 \mathrm{~nm}$ ) every $2 \mathrm{~h}$ (in total $24 \mathrm{~h}$ ) in both free nutrient medium (control) and medium containing toxicant $-\mathrm{EG}_{2}-\mathrm{Arg}-\mathrm{EG}_{4}$ (Figs. 2-4).

Initially the character of the test-microorganisms growth in the free nutrient medium (control) during $24 \mathrm{~h}$ was studied (Figs. 2-4, curves 1). The microorganisms were found to have different stages of development the logarithmic phase for Escherichia coli and Mycobacterium album lasted up to $18 \mathrm{~h}$, whereas the logarithmic phase for Bacillus subtilis lasted up to $22 \mathrm{~h}$. The obtained curves allowed to determine at which stage of development the test-cultures might be sensitive towards polycations.
The biocidal compound - $\mathrm{EG}_{2}-\mathrm{Arg}-\mathrm{EG}_{4}$ was added to the culture medium at a concentration $0.1 \mathrm{mg} / \mathrm{mL}$. The obtained results are given in Figs. 2-4 (curves 2). The results showed that the inhibition of development of Escherichia coli by polycation $\mathrm{EG}_{2}-\mathrm{Arg}-\mathrm{EG}_{4}$ was not observed during $10 \mathrm{~h}$ (Fig. 2, curve 2). Biocidal action of the compound was observed after $10 \mathrm{~h}$ and lasted for ca. $12 \mathrm{~h}$, i.e. during the whole period $(24 \mathrm{~h})$ of cultivation.

The suppression of Bacillus subtilis growth by $\mathrm{EG}_{2}$-Arg-EG $\mathrm{EG}_{4}$ was not observed during $10 \mathrm{~h}$ of cultivation (Fig. 3, curve 2), and the biocidal activity of $E_{2}-A r g-E G_{4}$ during next $8 \mathrm{~h}$ of cultivation of the microorganism was quite weak, whilst during the remaining period the development of culture was significantly low compared to the control test. The biocidal effect of $\mathrm{EG}_{2}-\mathrm{Arg}-\mathrm{EG}_{4}$ on the growth of Mycobacterium album was stronger compared to other experimental test-cultures (Fig. 4, curve 2). Under the influence of the polycation the microorganism's development was not observed for the first $6 \mathrm{~h}$; during the rest period growth of the microorganism was observed, however, it was significantly low than the development in the free medium.

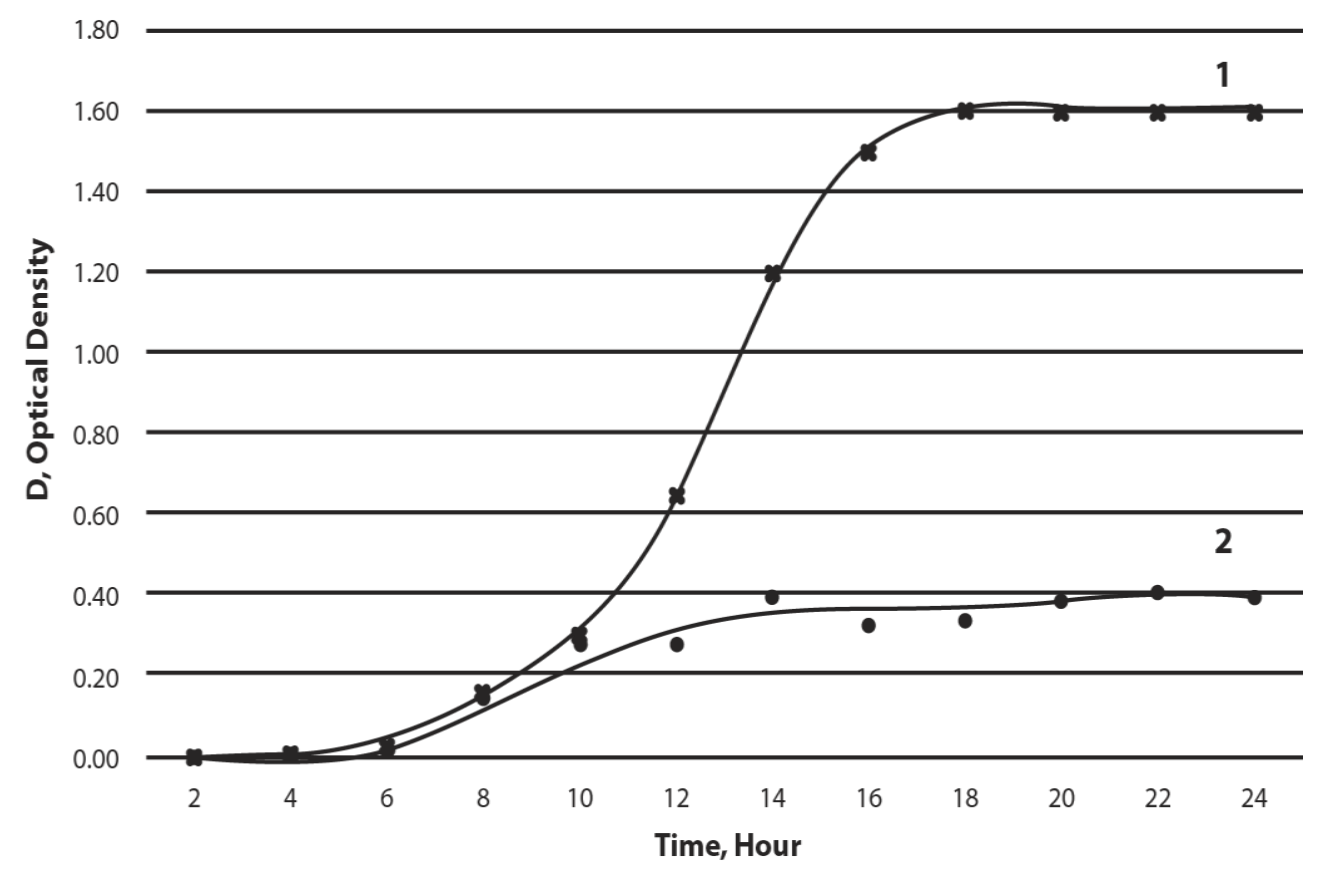

Fig. 2 The inhibition of Escherichia coli growth by PEEUR EG EArg-EG $_{4}$ : 1. In pure growth medium; 2. In growth medium containing PEEUR (0.1 mg/mL). 


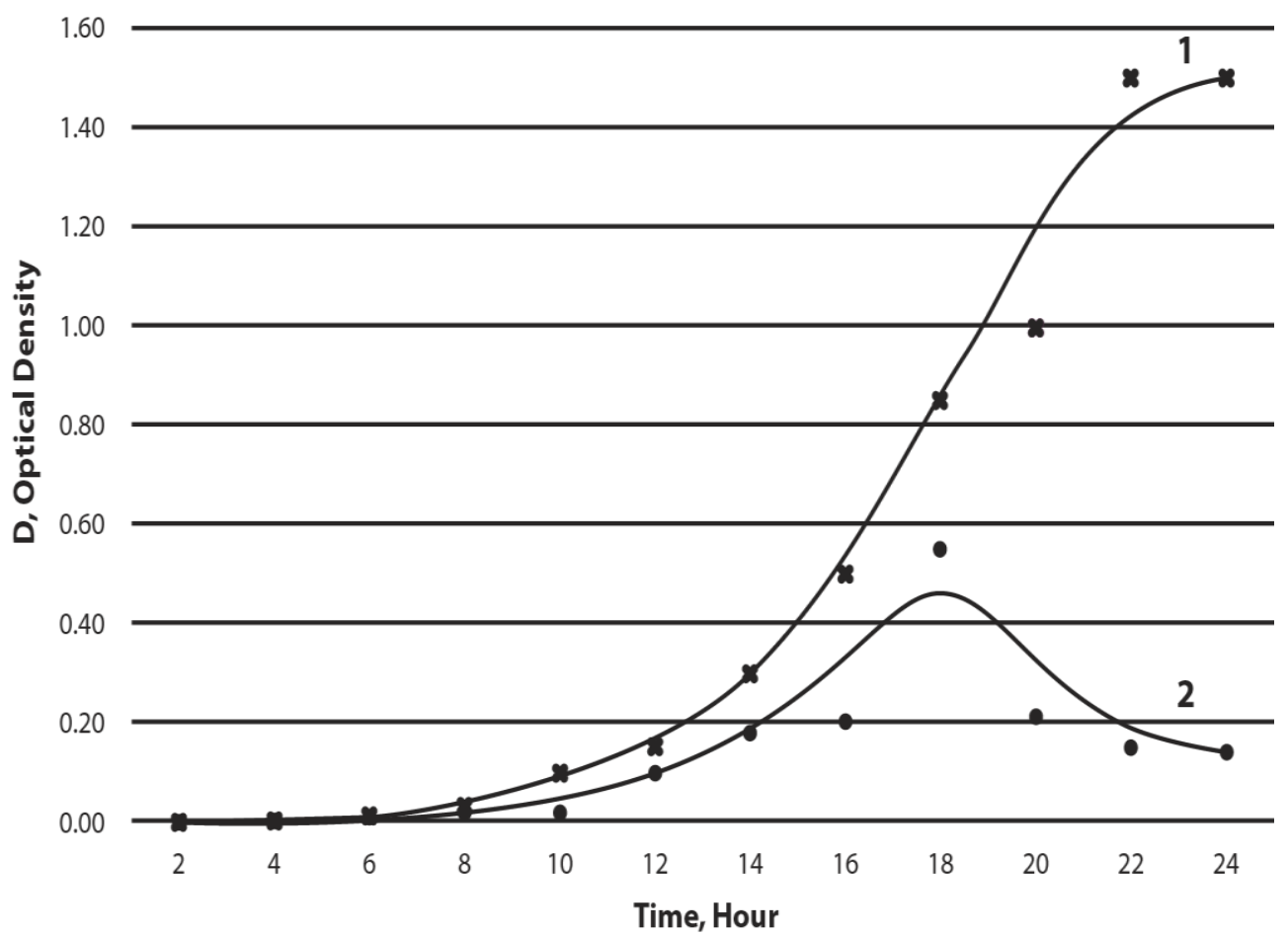

Fig. 3 The inhibition of Bacillus subtilis growth by PEEUR EG EG-Arg-EG $_{4}$ : 1. In pure growth medium; 2. In growth medium containing PEEUR (0.1 mg/mL).

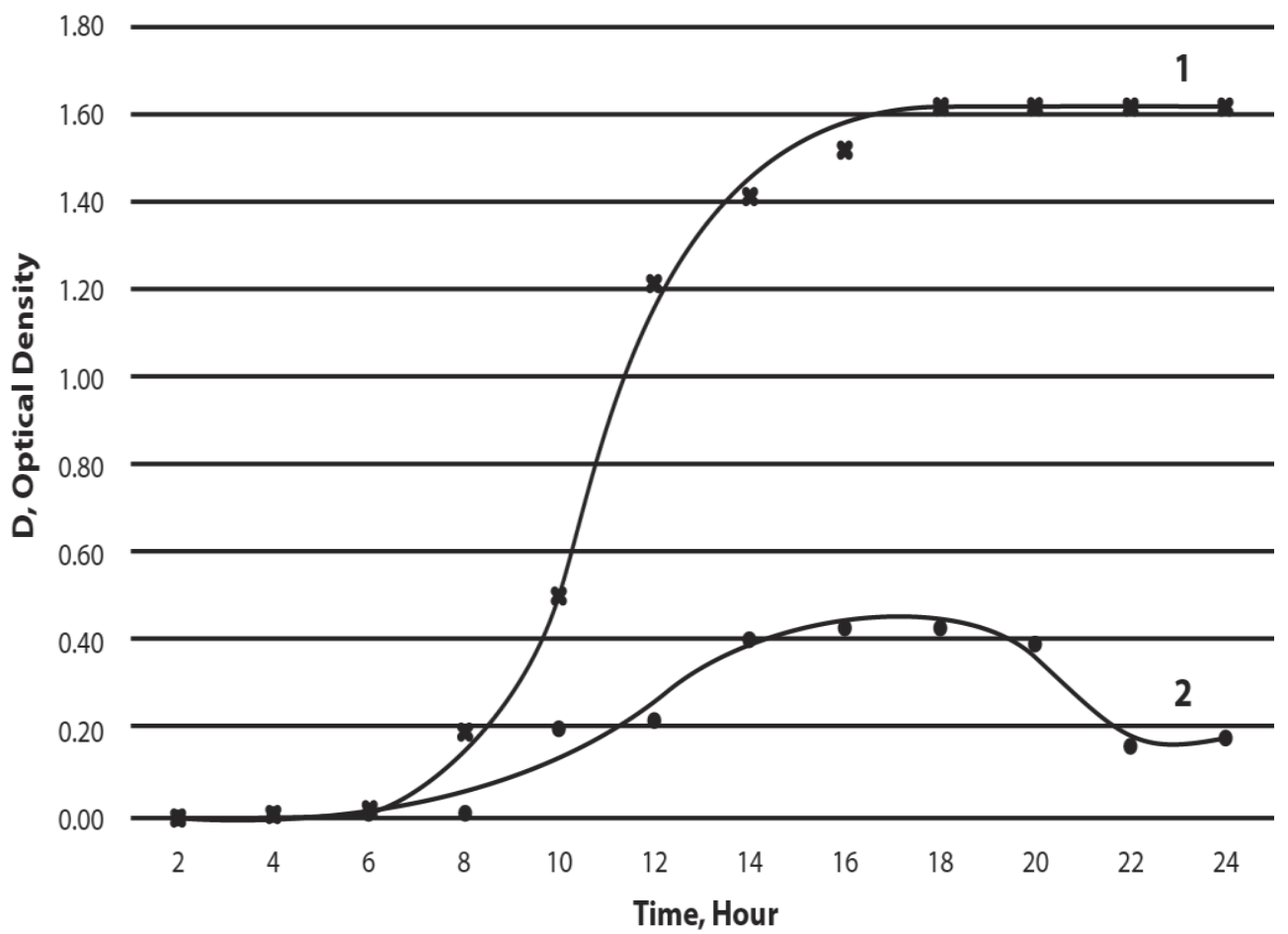

Fig. 4 The inhibition of Mycobacterium album growth by PEEUR EG EArg-EG $_{4}$ : 1. In pure growth medium; 2. In growth medium containing PEEUR (0.1 mg/mL). 


\section{Conclusions}

Biocidal activity of new cationic polymers: PEUs 1-Arg-2 and 1-Arg-3, poly (ester urethane) EG-Arg-3 and PEEURs EG EArg-2, EG $_{2}$-Arg-3, $\mathrm{EG}_{2}-\mathrm{Arg}-\mathrm{EG}_{2}$ and $\mathrm{EG}_{2}-\mathrm{Arg}-\mathrm{EG}_{4}$ at concentrations $10^{-1} \mathrm{mg} / \mathrm{mL}, 10^{-2} \mathrm{mg} / \mathrm{mL}$ and $10^{-3} \mathrm{mg} / \mathrm{mL}$ against seven test-microorganisms was studied.

The obtained results showed that the new cationic polymers suppressed the growth of the studied microorganisms, had a selective bactericidal activity and the bactericidal activity of the tested cationic polymers strongly depended on their chemical structure. The biocidal activity of polycation $\mathrm{EG}_{2}-\mathrm{Arg}-\mathrm{EG}_{4}$ towards Escherichia coli, Bacillus subtilis, and Mycobacterium album revealed mainly during logarithmic phase of development of the microorganisms.

Taking into account a high cytocompatibility of the studied cationic polymers, they can be considered as promising biocidal agents. Expanding the spectrum of biocidal activity can be achieved by mixing of the studied cationic polymers.

\section{References}

[1] Siedenbiedel, F., and Tiller, J. C. 2012. "Antimicrobial Polymers in Solution and on Surfaces: Overview and Functional Principles." Polymers 4: 46-71.

[2] Lode, H. M. 2009. "Clinical Impact of Antibiotic-Resistant Gram-Positive Pathogens." Clin. Microbiol. Infect. 15: 212-7.

[3] Gonzales, F. P., and Maisch, T. X. F. 2010. "Drugs: A New Family of Antibacterials." Drug News Perspec. 23: 167-74.

[4] Kenaway, E. R., Worley, S. D., and Broughton, R. 2007. "The Chemistry and Applications of Antimicrobial Polymers: A State of the Art Review." Biomacromolecules 8 (5): 1359-84.

[5] Zasloff, M. 2002. "Antimicrobial Peptides of Multicellular Organisms." Nature (London) 415: 389-95.

[6] Patch, J. A., and Barron, A. E. 2003. "Helical Peptoid Mimics of Magainin-2-amide." J. Am. Chem. Soc. 125: 12092-3.

[7] Jenkins, S., Addy, M., and Wade, W. 1988. "The Mechanism of Action of Chlorhexidine. A Study of Plaque Growth on Enamel Inserts in Vivo." J. Clin.
Periodontol. 15 (7): 415-24.

[8] Manetti, F., Castagnolo, D., Raffi, F., Zizzari, A. T., Rajamäki, S., D'Arezzo, S., Visca, P., Cona, A., et al.. 2009. "Synthesis of New Linear Guanidines and Macrocyclic Amidino Urea Derivatives End Owed with High Antifungal Activity Against Candida Spp.and Aspergillus Spp.” J. Chem. Med. 52 (23): 7376-9.

[9] Hensler, M. E., Bernstein, G., Nizet, V., and Nefzi, A. 2006. "Pyrrolidine-bis-cyclic Guanidines with Antimicrobial Activity Against Drug-resistant Gram-Positive Pathogens Identified from a Mixture-Based Combinatorial Library." Bioorganic \& Medicinal Chemistry Letters 16 (19): 5073-9.

[10] Ikeda, T., Ledwith, A., Bamford, C. H., and Hann, R. A. 1984. "Interaction of a Polymeric Biguanide Biocide with Phospholipid Membranes." Biochim. Biophys. Acta Biomembr. 769: 57-66.

[11] Ikeda, T., Hirayama, H., Yamaguchi, H., Tazuke, Sh., and Watanabe, M. 1986. "Polycationic Biocides with Pendant Active Groups: Molecular Weight Dependence of Antibacterial Activity." Antimicrobial Agents and Chemotherapy 30 (1): 132-6.

[12] Jahnsen, R. D., Haney, E. F., Franzyk, H., and Hancock, R. E. W. 2013. "Characterization of a Proteolytically Stable Multifunctional Host Defense Peptidomimetic." Chem. Biol. 20: 1286-95.

[13] Lu, H., Zhang, S., Wang, B., Cui, S., and Yan, J. J. 2006. "Inhibition of Protein Kinase $\mathrm{C}$ by Cationic Amphiphiles." Controlled Release 114 (1): 100-9.

[14] Memanishvili, T., Zavradashvili, N., Kupatadze, N., Tugushi, D., Gverdtsiteli, M., Torchilin, V. P., Wandrey, C., Baldi, L., et al.. 2014, "Arginine-Based Biodegradable Ether-Ester Polymers of Low Cytotoxicity as Potential Gene Carriers." Biomacromolecules 15: 2839-48.

[15] Birger, M. O. 1982. In Guide for Investigations in Microbiology and Virology. ed. Moscow: Meditsina.

[16] Krasilnikov, N. A. 1950. In Actinomycete-antagonists. ed. Moscow: Academy of Sciences of USSR.

[17] Tepper, E. Z., Shilnikova, V. K., and Pereverzeva, G. M. 2003. In Practical Handbook in Microbiology. ed. Moscow: Mir.

[18] White, D. G., Acar, J., Anthony, F., Franklin, A., Gupta, R., Nicholls, T., Tamura, Y., Thompson, S., et al.. 2001. "Standardisation and Harmonisation of Laboratory Methodologies for the Detection and Quantification of Antimicrobial Resistance." Rev. Sci. Tech. Off. int. Epiz. 20: 849-58.

[19] Leegard, T. M., Caugant, D. A., Froholm, L. O., and Hoib, E. A. 2000. "Apparent Differences in Antimicrobial Susceptibility as a Consequence of National Guidelines." Clin. Microbiol. Inf. Dis. 6: 290-3.

[20] NCCLS (National Committee for Clinical Laboratory 
Standards). 2002. Document M39-A. Analysis and Presentation of Cumulative Antimicrobial Susceptibility Test Data: Approved Guideline. NCCLS document M39-A. NCCLS, 940 West Valley Road, Suite 1400, Wayne, Pennsylvania, USA.

[21] Kahlmeter, G., Brown, D. F. J., Goldstein, F. W., Macgowan, A. P., Mouton, J. W., Osterlunda, A., Rodloff,
A., Steinbakk, M., et al.. 2003. "European Harmonization of MIC Breakpoints for Antimicrobial Susceptibility Testing of Bacteria." J. Antimicrob. Chemother. 52: 145-8.

[22] OIE (World Organization for Animal Health). 2003. OIE International Standards on Antimicrobial Resistance., Paris, France. 